\title{
Does Iran Scientific Development Support Its Sustainable Development?
}

\author{
Alireza Nasiri ${ }^{1}$, Zobia Hussain ${ }^{1} \&$ Dmirtii Kochin ${ }^{1}$ \\ ${ }^{1}$ Global Inistitute of Management and Economics, Dongbei University of Finance and Economics, Dalian, China \\ Correspondence: Alireza Nasiri, Global Inistitute of Management and Economics, Dongbei University of Finance \\ and Economics, Dalian, China. Tel: 86-134-7870-1203. E-mail: anasiri@ut.ac.ir
}

Received: February 6, 2015 Accepted: March 4, 2015 Online Published: May 28, 2015

doi:10.5539/jsd.v8n3p89 URL: http://dx.doi.org/10.5539/jsd.v8n3p89

\begin{abstract}
Over the last few decades, Iran's scientific development has been on the increase, and it is now the fastest growing country in scientific development, and is currently ranked at 17 . Yet there are few papers which address Iran's sustainable development, and the implications that arise from the development of science. In this paper we therefore aim to answer whether or not Iran's scientific development supports its sustainable development. To address both parts we have taken data from 1998-2012, and have looked at scientific development, as well as the development of social, economic, and environmental sustainability. What we found was that all areas of sustainability along with scientific development have significantly increased over the years, with subject areas such as Medicine, Chemistry and Engineering producing the highest number of publications in 2012. As well as this, the data clearly shows that all areas have followed a similar trajectory, and show similar percentage changes year on year. Looking at the data alone we can say that Iran's scientific development does support sustainable development, however this is not the case when we include performance data. Both sets of data show that all areas of sustainability and science in general have increased over the last 15 years, however they differ with regards to the areas in specific. These differences however can be attributed to many points. Further research could look into finding a more robust way of defining the output of research, using a different approach to categorise subject areas, and collecting qualitative data to support the data collected.
\end{abstract}

Keywords: sustainable development, development strategy, scientific development, social development, environmental development, Iran

\section{Introduction}

\subsection{Introduce the Problem}

Iran has become the fastest growing country in scientific development, going from a ranking of 49 in 1998 to a ranking of 17 in 2013, according to the SCImago Journal and Country Rank (SCImago Journal and Country Rank, 2013). What is more important is that not only has the output of publications increased, but the actual quality of the papers has also increased, as now many of the journals are handled by expert editors, and are issued in high-ranking journals such as PubMed and Scopus (Kharabaf \& Abdollahi, 2012). In 2012 Iran had also invested $0.5 \%$ of its GDP to research and development, and even though more developed countries spend up to $1.4 \%$ (Kharabaf \& Abdollahi, 2012), it shows Iran's increasing commitment to scientific research and development, and the amount they are willing to invest to continue the growth. This is especially evident in the fields of medicine and biotechnology, with Iran ranking 14 among 46 world countries that are active in the latter field in 2013 (FARS new agency, 2013). It is not surprising that the scientific development has in fact contributed to the increase in social development and export markets (FARS new agency, 2013), and now that Iran is at a point where it is close to becoming a developed country, supporting itself and the countries sustainability, with the leaps its making within science is becoming more and more important.

Sustainable development itself refers to "development that meets the needs of the present without compromising the ability of future generations to meet their own needs" (World Commission on Environment and Development, 1987). Since the topic of sustainable development has been raised, there have been many interpretations for the definition of sustainability, what it should encompass and how it can be achieved, however they all agree that sustainable development concerns three areas: economic, social, and environmental (World Commission on Environment and Development, 1987; Carley \& Christie, 2000; Colantonio, 2007). 
Even though people have long been aware of sustainability, it is only in recent years that it is becoming of more importance as resources are limited, consumption is increasing, and our ecosystem is being negatively affected (Drake \& Spinler, 2013). As a result many countries and businesses are now trying to be sustainable and lessen their affect on the world. Achieving this generally means addressing all the 3 elements of sustainability: economic, social, and environmental, simultaneously (Murphy, 2012). However, this seems to not be happening as social sustainability is the least developed of the 3 areas, which is confirmed from the lack of understanding of the dimension (Partridge, 2005).

Looking at Iran's sustainable development specifically it seems that there has been a marked improvement over the years. For instance, the Human Development Index, which measures progress regarding access to knowledge, defined by years at school, standard of living, defined by the Gross National Income (GNI) per capita (in 2005 constant dollars), and life expectancy, increased from 0.540 to 0.754 between 1990-2012. Access to knowledge went from 9.2 to 14.4 years, life expectancy went from 61.8 to 73.2 , and standard of living went from 6189 to 10695, over the same time period (Human Development Report, 2013). This data certainly goes to show a steady improvement within the social aspect of sustainability, and one can assume that it will continue to increase as time goes by. Gross National Income can also reflect an increase within the economy and shows that it is growing and getting stronger over the years, so also reflects the increase in economic development.

This is obviously not the only indicator of Iran's increase in sustainable development, World Development indicators from The World Bank also show there has been an increase in stocks traded between 1998-2012 going from US\$1388979771.4 to US\$22061050721 (The World Bank, 2013), this combined with the GNI further supports the fact that economic development has been of the upmost importance in the last few decades in Iran, and has enjoyed a significant increase. Mobile subscriptions have also gone up from 389974 to 76424443 (The World Bank, 2013), and as mentioned above the scientific development has also been fast-growing, both reflecting the push in technology, innovation and research, all strengthening the environment and social aspects of sustainability. On the other hand, $\mathrm{CO} 2$ emissions (metric tonnes per capita) have substantially increased during the period of 1998-2010, going from 4.9 to 7.7, and industrial nitrous oxide emissions (thousand metric tonnes of CO2 equivalent) have gone from 499.4 to 882.5 between 2000-2010 (The World Bank, 2013). This is most probably down to an increase in industry, which still illustrates the increase in economy and social areas, but also highlights the compromise that has been made with regards to the environment, which can also go to some extent in showing the priorities of Iran being mostly in economic and social development (Atabi, 2004).

It is already apparent that Iran has made such significant strides within scientific development, and has become the fastest growing within this regard, and has also made great strides in improving areas within sustainable development, however not all areas are being taken care of as was shown by the increase in $\mathrm{CO} 2$ and nitrous oxide emissions. Sustainable development has also become something of great importance, and with negative effects on the environment and resources becoming scarce, it is important to see whether Iran is solely focused on becoming the best with regards to research and science, or is it in fact also taking into account the importance of sustainable development. It seems that they are becoming more aware of this themselves as their science has had a positive effect on social welfare, and technology amongst other things; however it is key to understand whether or not Iran is trying to support all aspects of sustainable development, or just a few. Taking this into account our question is: Does Iran's scientific development support sustainable development. In answering this question we will not only look at the changes that have happened over the years, but will also be able to make predictions for the future. To answer the question we will firstly look into current literature around this topic to establish what we already know and where the gaps are, after which we will establish the research methods, collect the results, and conduct in-depth analysis.

\subsection{Literature Review}

In order to review literature regarding this topic we have looked at many papers from several journals including: A Brief Review of Science and Technology by M. Molanezhad, Trends in Basic Sciences in Contemporary Iran: Growth and Structure of Mainstream Basic Sciences by Shapour Etemad and Yousef Sobouti, Science and innovation in Iran edited by Ardol S Soofi and Sepehr Ghazinoory, Energy and Sustainable Development in Iran by Morteza Sabetghadam, and Technology and Innovation Policy Review from the United Nations Conference on Trade and Development. As well as this, we have also used the Iranian Research Organization for Science and Technology (IROST).

The article by Morteza Sabetghadam is the "first sustainable energy watch report for Iran", where 8 indicators including: sustainability, carbon dioxide emissions, and clean energy are used to show whether Iran is close to the global average and if they are working on improving these certain areas. The paper discusses the success of 
the mass electrification program which has meant that Iran has become the "closest to the sustainability target" on the indicator with regards to access to electricity (Sabetghadam, 2006). With regards to the other fields, many have shown an improvement, however in areas such as carbon dioxide emission and energy productivity there has been deterioration. This could be a result of the growing market, Iran's drive towards industry and the reliance on oil products, which have meant that such aspects have been compromised. It has also been reported that there have been significant improvements in electricity generation and an increase in projects regarding renewable energy, which shows one case where Iran is using scientific development to support sustainability. It is stated that currently there is a demand for development in Iran, and analysts conclude that if the correct development strategy is implemented then it will bring more economic benefits to Iran, along with an improvement in the indicators (Sabetghadam, 2006).

Similarly Etemad and Sobouti also discuss science and the future development of countries. They look at science journals and the development of Iranian society during 1980-2005 to analyse the data provided. Here they discuss how the performance in science raises the hope that Iran may have reached the threshold of self-sustainability and is therefore able to now develop on its own to lead industry and business. They also mention that over the years there has been a movement from chemistry to medicine, showing how Iran is progressing with the times, and is adapting to what is relevant in science (Etemad \& Sobouti, 2008).

The major theme of the other journals, including the articles mentioned, was scientific development and innovation, and many illustrated the achievements of the Iran over the years. There was a mention of the considerable success in the field of high technologies and nuclear industries, as well as developing new sciences, such as laser, nanotechnology, and microelectronics. Other achievements listed include: the widespread use of information technologies, development of scientific institutions, the production of various robots, and successful performances in various scientific Olympiads including mathematic, physics, chemistry, and computer science. As well as this, Iran took first place in the world of scientific and inventive competition in Switzerland, the second place at the International Exhibition in Moscow.

The articles here highlight the abundance of information on Iran's scientific development, and we are also well aware of sustainability and what it entails as it is heavily written about, however there are not many papers which address whether or not Iran's scientific development supports sustainable development. Literature regarding our topic and research question is limited. Since, sustainability has increasingly become more important throughout the years, and it has become necessary to preserve our resources and support all areas of society, it is essential to establish whether or not Iran's scientific development is be able to do this, or does it in fact compromise these aspects in order to continue increasing growth. As well as this, we will also be able to gain an insight into future trends to explain if sustainable development will be supported in the future.

\section{Method}

We used Mixed Method, to answer the question whether Iran's scientific development supports sustainable development. We are using both types of quantitative and qualitative data so we are able to collect empirical data which could clearly show us trends, an insight into future trends, percentages, and associations so we can gain precise information and back up results with testable data. Qualitative data is collected so we can further support the results and supplement them with additional back up. With both kinds of data we are able to understand the topic through real views and perceptions, and then be able to build a more precise picture using qualitative data.

Regarding the quantitative research we have chosen to cover 15 years of scientific research (1998-2012) as it fully covers the period of when Iran's scientific development really took off.

\subsection{Sample Size and Selection of Sample}

With this we are also able to back up the theories we have, and compare to secondary data which we also collected.

To measure scientific development we looked at the number of articles published, within the following categories. This not only gives us a total number of publications per year, but also shows us which areas are focused on and the trends over the years. Indicators, such as publication and citation rates, are increasingly being used to analyse scientific development and their relation to sustainable development, and therefore we adopted a similar approach when answering our research question (Kharabaf \& Abdollahi, 2012). We looked at 236586 publications from 119 different journals in order to fully answer the question. The subject areas that are categorised into Economic, Social, and Environment are: Agricultural and Biological Sciences, Arts and Humanities, Biochemistry, Genetics and Molecular Biology, Business Management and Accounting, Chemical Engineering, Chemistry, Computer Science, Decision Sciences, Dentistry, Earth and Planetary Sciences, 
Economics, Econometrics and Finance, Energy, Engineering, Environmental Science, Health Professions, Immunology and Microbiology, Materials Science, Mathematics, Medicine, Multidisciplinary, Neuroscience, Nursing, Pharmacology, Toxicology and Pharmaceutics, Physics and Astronomy, Psychology, Social Sciences, and Veterinary. This is per the SCImago Journal and Country Rank listing.

To categorise the topics we used the jury method whereby we select and bring together 2 panels of esteemed individuals, who work within the economics, social, and environment fields, and so can provide us with background information, experiences, and opinions, in order to make an executive decision. Their views combined and averaged to decide what areas go into the economic, social, and environmental areas.

\subsection{Sources of Data}

Primary sources of data include information from the SCImago Journal and Country Rank site.

Secondary sources of data include collecting current journals regarding our topic, and information from the International Science Community, the United Nations, the World Bank, and Human Development Reports.

\subsection{Collection of Data}

To collect the data we applied the library methods to collect the information. We also collected publications regarding Iran scientific development and sustainability for a comprehensive literature review, and to supplement our data.

\subsection{Data Analysis Strategies}

We used statistical analysis to process the data, and to establish trends, compute statistics. This allows us to clearly and accurately analyse the vast amount of data we collect, and helps to represent a relationship in the form of graphs, charts, and tables. Data analysis include: number of publications within each category, percentage of publications within the economic, environmental, and social areas, number of publications in total per year, trends to show the shift in focus over the years, and trends to illustrate whether or not development is sustainable. To establish if there is any relationship between scientific development and sustainable development we illustrate the correlation between these 2 variables, which show the total number of publications per year, representing scientific development, along with the number of publications per year in each area of sustainable development. If we can show that as scientific development increases so does sustainable development, then we can assume that there is a positive relationship between scientific development and sustainable development, and vice versa.

Relevant secondary information just be collected to supplement the data we collect, it does not need analysing as it have been by the original authors, but included in the discussion.

\section{Results}

The results we have gained in this research can be classified in following three categories:

\subsection{Publications}

The table 1 is to show the number of publications in each subject area from 1998-2012. Here we can see the changes for each individual subject, as well as overall changes within each area of sustainability.

In the Table 1 subject area are categorized in sustainable development three dimensions

The key below should be referred to when looking at the table. Subject areas 1-10 are within Environmental sustainability, subject areas 11-24 are within Social sustainability, and subject areas 25-27 are within Economic sustainability. The colours used to distinguish them are the same whenever the different areas are being represented. In order to avoid mass data presentation in this paper we present only three snapshots in these 15 years $(1998,2005$ and 2012).

As table 1 display the change in number of publications over the 27 subject areas. In the area of Environmental sustainability the number of publications has gone up from 953 in 1998, to 29672 in 2012, again an increase of more than $3000 \%$. Similarly, in the area of Social sustainability the number of publications has gone from 388 in 1998, to 16339 in 2012, this is an increase of more than $4000 \%$. In the area of Economic sustainability the number publications has also gone up from 86 in 1998, to 2747 in 2012, an increase of more than 3000\%. Overall we can see that Environmental sustainability has been a major focus in the years, however Social sustainability has seen the most significant increase over the years, in contrast Economic sustainability is still lagging behind, even though it is also on the increase, and has increased at a similar rate as Environmental sustainability and scientific development in general. More specifically there has been a shift in focus from Chemistry (area with Environmental sustainability) to Medicine (area within Social sustainability). 
In contrast, in 1998 the most neglected area was Nursing, whereas in 2012 the most neglected area was Health profession, both areas within Social sustainability.

Table 1. Number of publication from 1998-2012 per subject area

\begin{tabular}{|c|c|c|c|c|c|c|c|c|c|}
\hline Row & Subject area & 1998 & 2005 & 2012 & Row & Subject area & 1998 & 2005 & 2012 \\
\hline 1 & $\begin{array}{l}\text { Agricultural and } \\
\text { Biological Sciences }\end{array}$ & 83 & 513 & 3417 & 15 & Health profession & 1 & 41 & 135 \\
\hline 2 & $\begin{array}{l}\text { Biochemistry, } \\
\text { Genetics and } \\
\text { Molecular Biology }\end{array}$ & 82 & 12 & 3807 & 16 & $\begin{array}{l}\text { Immunology and } \\
\text { microbiology }\end{array}$ & 23 & 171 & 933 \\
\hline 3 & Chemical engineering & 72 & 454 & 2077 & 17 & Medicine & 165 & 1545 & 7711 \\
\hline 4 & Chemistry & 236 & 1271 & 3902 & 18 & Multidisciplinary & 14 & 48 & 921 \\
\hline 5 & $\begin{array}{l}\text { Earth and Planetary } \\
\text { science }\end{array}$ & 67 & 204 & 975 & 19 & Neuroscience & 9 & 67 & 327 \\
\hline 6 & Energy & 22 & 102 & 917 & 20 & Nursing & 1 & 24 & 155 \\
\hline 7 & Engineering & 161 & 1106 & 6127 & 21 & $\begin{array}{l}\text { Pharmacology, } \\
\text { Toxicology and } \\
\text { pharmaceutics }\end{array}$ & 66 & 237 & 1043 \\
\hline 8 & $\begin{array}{l}\text { Environmental } \\
\text { science }\end{array}$ & 33 & 245 & 2084 & 22 & Psychology & 2 & 21 & 225 \\
\hline 9 & Material science & 88 & 711 & 3728 & 23 & Social science & 8 & 75 & 1249 \\
\hline 10 & $\begin{array}{l}\text { Physics and } \\
\text { astronomy }\end{array}$ & 109 & 472 & 2638 & 24 & Veterinary & 27 & 87 & 535 \\
\hline 11 & Arts and Humanities & 2 & 17 & 225 & 25 & $\begin{array}{l}\text { Business, } \\
\text { Management and } \\
\text { Accounting }\end{array}$ & 6 & 17 & 243 \\
\hline 12 & Computer science & 54 & 412 & 2354 & 26 & $\begin{array}{l}\text { Economics, } \\
\text { econometrics and } \\
\text { finance }\end{array}$ & 2 & 4 & 140 \\
\hline 13 & Decision science & 15 & 57 & 358 & 27 & Mathematics & 460 & 4068 & 637 \\
\hline 14 & Dentistry & 1 & 22 & 168 & & & & & \\
\hline
\end{tabular}

With regards to Social sustainability it seems that the only area of focus is Medicine, with 7711 publications published in 2012 within the area, and it has significantly increased over the years, so much so, that is was the most researched area in 2012. Regarding Environmental sustainability the main areas of focus are Chemistry, with 3902 publications published in 2012 within the area, and Material science, with 3728 publications published in 2012 within the area, and overall the area in general has also significantly increased.

Table 2. Total publication per S.D dimensions from 1998-2012

\begin{tabular}{cccc}
\hline & Environment & Social & Economy \\
\hline 1998 & 953 & 388 & 468 \\
2005 & 5636 & 2783 & 4089 \\
2012 & 29672 & 13075 & 1020 \\
\hline
\end{tabular}


Likewise, table 2 shows the overall change within the 3 dimensions of sustainability, from 1998 to 2012. Regarding Scientific development, we can see that the number of publications has gone up from 1809 to 43767 during the period of 1998-2012, which is an increase of more than $3000 \%$.

In addition, in figure 1 we can observe that the total number of publications in S.D dimensions since 1998 to 2012. Iran published a total number of 13181 publications in economics, 77978 in social, and 147387 in environmental subjects in this period.

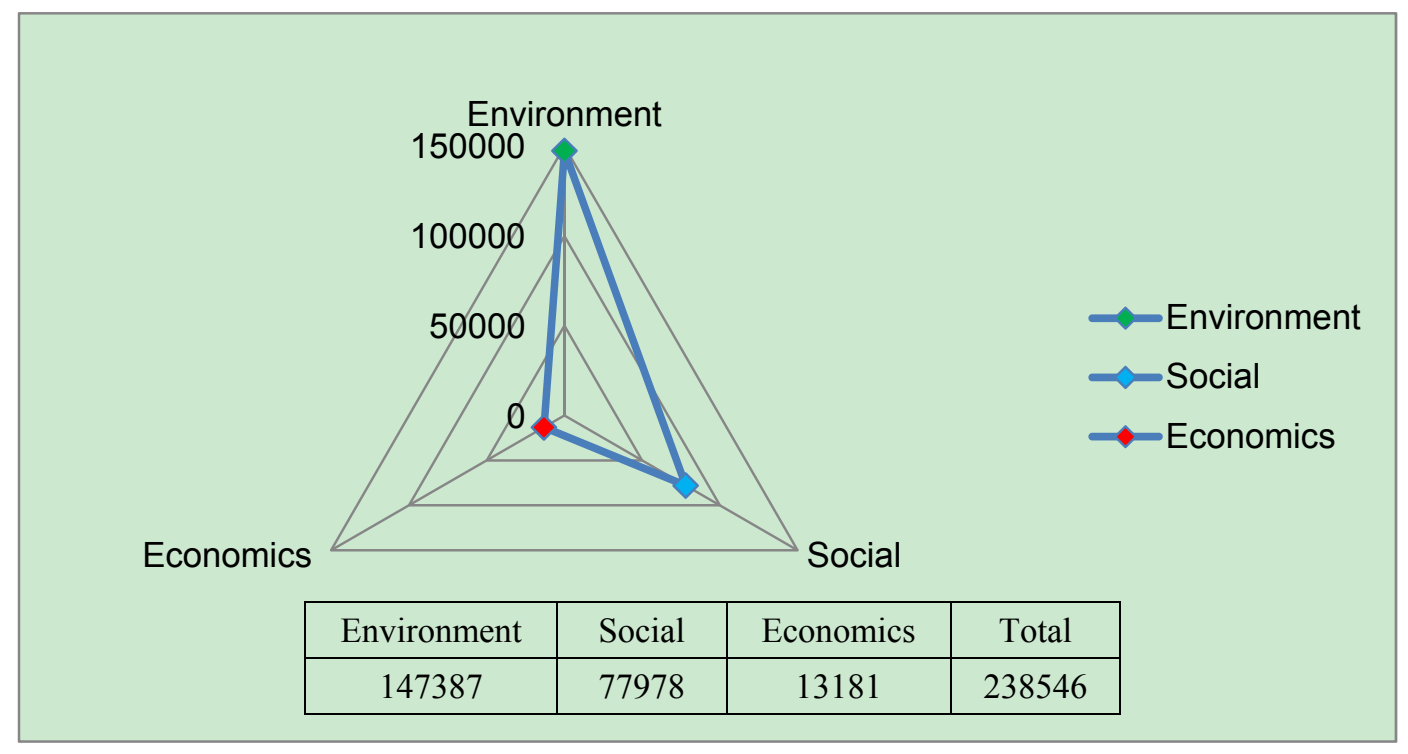

Figure1. Total number of publications in each S.D dimensions since 1998 to 2012

Moreover, figure 2 provides the percentage of publication in each dimension. Economics dimension has the lowest proportion with $5 \%$, and then followed by social with $33 \%$, and finally environment with the highest percentage of publications that is $62 \%$. These percentages indicate the research direction and the focuses area in Iran in the given period.

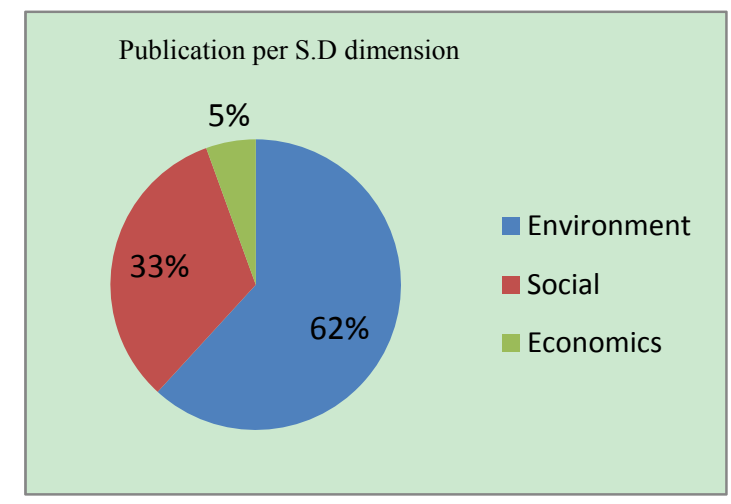

Figure 2. Percentage of publications per S.D dimensions from 1998 to 2012

\subsection{Trends in Scientific Developments}

One of the indicators that could help us understand the research direction and focuses in a longitudinal study is trend. We try to realize the direction of the research according to three sustainable development dimensions in Iran. 


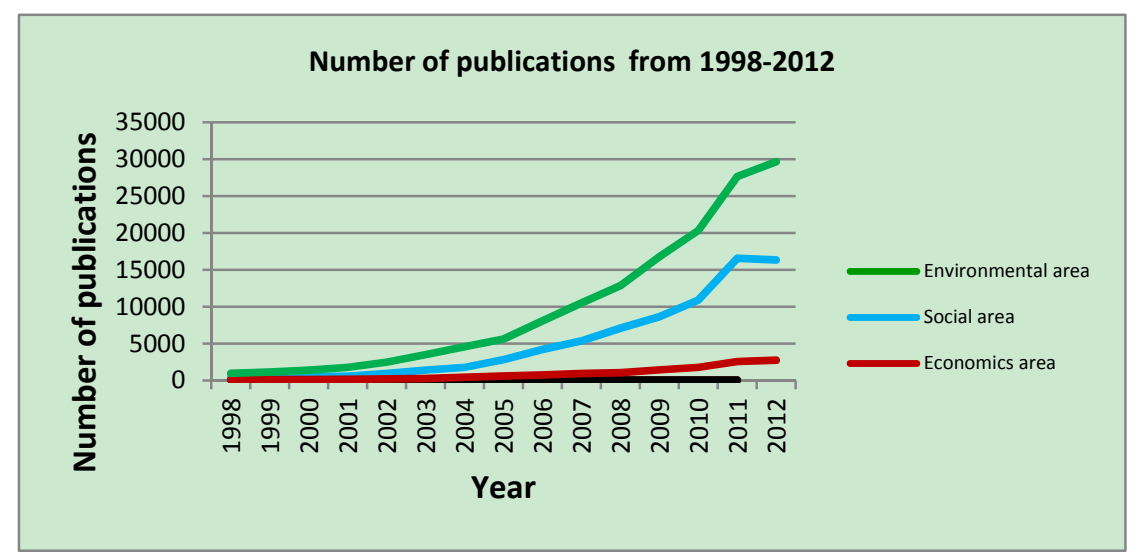

Figure 3. Number of publications within three dimensions of S.D and scientific development from 1998-2012

Figure 3 indicates that there has been an increase in all of the areas of sustainability over the years, and in the overall development of science. However the highest number of publications has been in Environmental sustainability, followed by Social sustainability, and finally Economics sustainability, and this trend has remained the same between 1998-2012. Nevertheless, Social sustainability takes a little dip between 2011 and 2012, where the number of publications goes from 16567 publications in 2011, to 16339 in 2012. More specifically, Scientific development has rocketed up from 1427 publications in 1998, to 48758 in 2012. Also environmental sustainability has gone from 953 publications in 1998, to 29672 in 2012, and Social sustainability has increased from 388 publications in 1998, to 16339 in 2012. Last but not least, economic sustainability has had a drastic increase from 86 publication in 1998, to 2747 in 2012.

\subsection{Relationships between Sustainable Development Dimensions}

It is important to make a balanced move in sustainability through stability of development in S.D dimensions. In this research we aim to understand the relationships between scientific and country development in Iran. In the table 3 we illustrate the relationships of three S.D dimensions in publications.

Table 3. Coefficient of correlations and covariance's between dimensions

\begin{tabular}{lll}
\hline Relationship between: & Coefficient of correlation & Covariance \\
\hline Environmental and Social & 0.998 & 54246816.543 \\
Environmental and Economics & 0.998 & 8590375.371 \\
Social and Economics & 0.997 & 789610.495 \\
\hline
\end{tabular}

Table 3 addresses the Coefficient of correlations and Covariance's between: a) Environmental sustainability and Social sustainability b) Environmental sustainability and Economic sustainability c) Social sustainability and Economic sustainability.

a) Here we can see the correlation of coefficient and covariance between Environmental and Social sustainability are 0.998 and 54246816.54 . This shows that there is in fact a strong positive relationship between the two (as they both increase from 1998-2012), and that they both move together in the same direction.

b) Data points the correlation of the coefficient and covariance between Environmental and Economic sustainability that are 0.998 and 8590375.37 . This shows that there is in fact a strong positive relationship between the two (as they both increase from 1998-2012), and that they both move together in the same direction. However, the number for covariance is smaller than the number for the relationship between Environmental and Social sustainability, suggesting that maybe the relationship between them is not as strong.

c) Likewise data points that the correlation of coefficient and covariance between Social and Economic sustainability is 0.997 and 789610.495 . This shows that there is in fact a strong positive relationship between the two (as they both increase from 1998-2012), and that they both move together in the same direction However, the number for covariance is smaller than the number for the relationship between Environmental and Social 
sustainability, and Environmental and Economic, suggesting that maybe the relationship between them is not as strong as either of the two.

\section{Discussion}

We have set out to answer the question whether or not Iran's scientific development supports sustainable development. Although literature looks at the general performance of Iran, very few publications address the overall sustainable development in Iran, we already know that Iran is a fast-developing country, and has come in leaps and bounds over the years. This is evident from general indicators which have been discussed above. The question is not trying to address the performance in specifics, but aims to look at if the development in Iran is supporting the overall sustainable development, and if it is equal across the 3 areas of sustainability. In this discussion we aim to explain the results we have collected, compare primary data to performance data, discuss future trends, and answer the question we have posed.

\subsection{Scientific Development}

Within Scientific development we can see a huge increase from 1998-2012, which is also reflected in performance data which shows that Iran has gone from a ranking of 53 in 1996, to 17 in 2013 (SCImago Journal and Country Rank, 2013). Iran's performance in some subject areas is even better and more remarkable. Table 4 illustrate Iran's rank in some subject areas in 2013.

This is well documented in journals and in the news, and is also reflected in our data, since there are no differences between the two, we do not need to further discuss this point, as it is fully established. However, the number of publications and the number of citations do not show the same trend, with the number of publications increasing, but the number of citations showing a significant decrease between 1998 and 2012. However we prefer to ignore the citation of publication in our research because this indicator mainly refers to the quality of the researches and publications rather than research directions (related to our topic) or applications. Citations are also subjective and often websites will state different number of citations for the same thing (Larsen and Ins, 2010), taking this into account it could be worth looking at several databases for citations to get a better picture of the true extent; and finally, often journals are found through different databases such as PubMed, and Google scholar, which could mean that these are cited instead of the actual journal, this could mean that publications are in fact cited more than it appears (Larsen \& Ins, 2010).

Table 4. Remarkable rank of Iran's scientific development in 2013

\begin{tabular}{lc}
\hline Subject Area & Work Rank \\
\hline Multidisciplinary & 8 \\
Fuel Technology & 7 \\
Energy Engineering and Power Technology & 9 \\
Nano Technology & 7 \\
Materials Chemistry & 10 \\
Polymers and Plastics & 8 \\
Chemical Engineering & 7 \\
\hline
\end{tabular}

Despite of the emphasis Iran has made in the "Iran's 20 years vision"; that country economical development should be based on science and knowledge, only one innovation has been patented from each of the 820 publications (Isna, 2015).

In summary, we argue that scientific development and research direction in Iran is moving forward in all of the three dimensions of sustainable development, however Iran has not yet been able to capture the value of them very well.

\subsection{Environmental Sustainability}

Environmental sustainability has also shown a large increase in publications over the last 15 years, and has also shown a steady percentage increase over the years.

With regards to Environmental sustainability, what is of more interest, are the differences between our data and performance data. As mentioned before, our data suggests that environmental sustainability has been focused 
upon highly and has always had the highest number of publications over the years; it also comprises of the most number of subject areas and so seems to be of great importance. As well as this, all areas have shown an increase with the exception of Agricultural and biological sciences, and Environmental sciences, which have both shown a slight dip between 2011 and 2012. Iran took several measures to protect and improve environmental sustainability. For instance Iran increased the national protected areas in both land and marine. Terrestrial percentages of land and marine areas increased respectively from $5.2 \%$ to $7.1 \%$, and $1.0 \%$ to $1.7 \%$ during the period of 1990 to 2010 . This shows that there has been a 36\% increase in protected land, and $70 \%$ in water. This resulted in Iran maintaining the same forest area (111 thousand $\mathrm{Sq} / \mathrm{Km}$ ) in the period of 1990-2010 and also keeping a average annual $0 \%$ of deforestation in same period, which is acceptable performance in the region.

Despite of all the inputs Iran put in place, outputs are not very permissible in all environmental aspects. Performance data however suggest that Environmental sustainability may in fact be the furthest behind in terms of growth, with natural resources depletion (\% of GNI) going from $10.3 \%$ in 1998 , to $19,6 \%$ in 2009 , agricultural nitrous oxide emissions (\% of total) going from $76.4 \%$ in 2000 , to $77.8 \%$ in 2010 , agricultural methane emissions (\% in total) going from $24.8 \%$ in 2000 , to $18.7 \%$ in 2010 , and $\mathrm{CO} 2$ emissions (metric tonnes per capita) going from $4.8 \%$ in 1998 , to $7.6 \%$ in 2010 . Data suggests that more and more of the environment resources are being used up, which leaves the environment itself lacking, however emissions into the air are overall increasing, with the exception of methane, so are continuing to pollute the atmosphere. In the same way, Iran's efforts in environmental scientific development could not improve water productivity which is at level 2 on the indicator of GDP/water use $\$ 2000$ per cubic meter.

Although this is not an exhausted list of environmental issues, it still goes a way to show that although our data suggests that environmental sustainability is flourishing, in actual reality this may not be the case. These differences may arise from the fact that the number of publications refers directly to output of research, however this does not necessarily mean that the research is a) being put to use yet b) directly effects environmental sustainability or c) is actually relevant to environmental sustainability as we know it.

Nevertheless, reports show that one of Iran's focus between 2012 and 2016 is to become more environmentally sustainable, which includes managing climate change and biodiversity, assessing environmental impacts, and reducing the consumption of hydro chlorofluor carbons by $10 \%$. Moreover, it has already upgraded 7 out of 10 cheetah habitats, and has developed the Carbon Sequestration project near Birjand (United Nations Development Programme, 2013). In fact, the entire report focuses on Environmental and Social sustainability only, which could either indicate that these areas have in fact been neglected in the past, and so now Iran is trying to focus on them more in order to become sustainable across all the areas, or that economic growth is stable, however these 2 areas have proved to be less so, so they are trying to bring these on par with the economic growth. Either way, it seems that they are currently in focus, possibly as these areas are becoming more and more important in the global perspective, and so will hopefully see some significant growth in the next few years.

\subsection{Social Sustainability}

Social sustainability has again shown a large increase in publications over the last 15 years, and has also shown a steady percentage increase over the years.

Again what is more important is the difference between our data and performance data relevant to Social sustainability. Here the differences are not as drastic as with Environmental sustainability, as both the data we collected and performance data suggest that Social sustainability has increased over the years, and is a focal point for Iran. This however could be due to the fact that as economy grows, social welfare etc is generally the first to benefit from it, so it could just be a ripple effect from the increase in economy, as oppose to an actual focal point. Regarding performance data the Human Development Indicators Index (Figure 4) has gone from approximately 0.64 in 1998, to 0.742 in 2013, showing a significant increase and growth in social welfare in Iran. As well as this, the health index itself is 0.839 , the education index is 0.707 , the income index is 0.69 , the non-income index is 0.769 , the gender inequality index is 0.496 , life expectancy is 73.2 , expenditure on health and on education (\% of GDP) is 2.2 and 4.7, respectively, the population living below $\$ 1.22$ PPP per day (\%) is $1.5 \%$, under 5 mortality (per 1000 live births) is 26 , electric power consumption (kwh) has gone from $8.83 \mathrm{E}+10$ in 1998 , to $1.99787 \mathrm{E}+11$ in 2010 . All these indicators reflect that social sustainability is high, and has come a long way over the years, and will continue to grow, as all indicators are on a positive trajectory. 


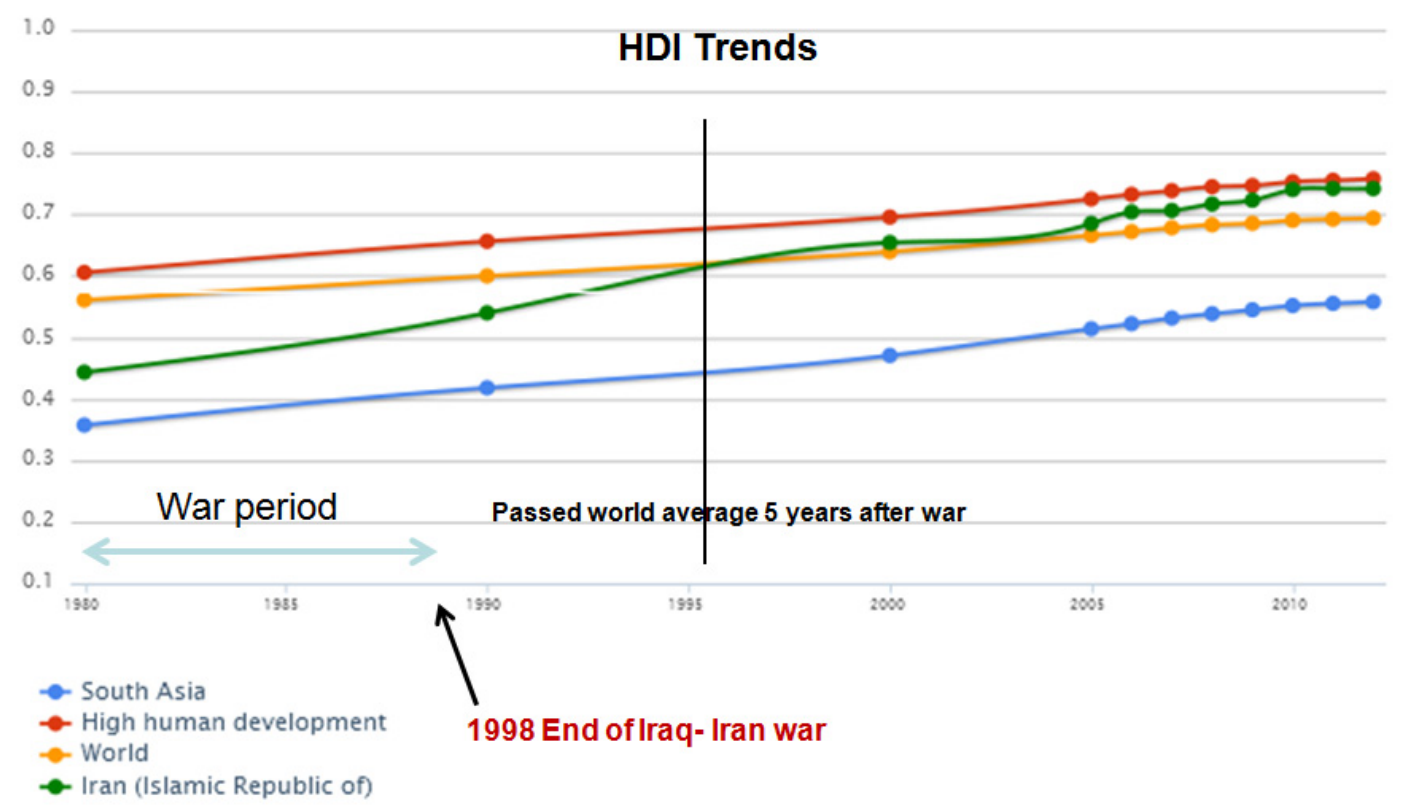

Figure 4. Human Development Index: Trends 1980-2013

Source: Human Development Report 2013 - http://hdrstats.undp.org/en/countries/profiles/IRN.html

The United Nations Development Programme data goes further to back this up, as it comments on diseases such as malaria showing a $60 \%$ drop since 1990 , and TB showing at $46 \%$ since 1990 , again suggesting that social welfare and social sustainability have been of great importance in Iran, and has increased over the years. As well as this, the report shows further plans, which aim to reduce poverty, and reduce the number of incidences of TB, malaria, and HIV.

Our data actually suggested that Nursing is one of the areas with the fewest number of publications, and therefore suggesting the least growth, however with index scores regarding health as high as they are, and data showing the incidences decreasing significantly, this cannot be true. These differences could be due to the fact that number of publications may not necessarily reflect growth and/or output of research, as discussed above. Also, Medicine had the most significant increase with regards to publications and was also the area with the highest number of publications in 2012, so it seems that the data itself has some contradictions, which could be lending itself to the differences.

In some medical subject areas, Iran's scientific performance is remarkable and it is even amongst the top 5 counties in the subject. For instance Iran was the first to introduce bio-artificial trachea to the world. However, the national wide health system (among the social factors) is still one of the main challenges that Iran has to struggle with. Iran only spends $5.6 \%$ of the GDP for the health system (World Bank, 2012). Iran announced a new national health system in 2013 and it increased the insurance cover but there is yet no available data regarding this matter.

\subsection{Economic Sustainability}

Economic sustainability has also shown a large increase in publications over the last 15 years, and has also shown a steady percentage increase over the years.

Again the differences between our data and performance data, is of most interest, as it shows great differences. Our data suggests that the number of publications are the least within Economic sustainability, and the percentage increase in this area is lower than Social sustainability. As well as this, our data suggests that some of the areas with lowest number of publications, so the least growth, are Economics, econometrics, and finance, and Business, management, and accounting. This however is not reflected in performance data which actually indicates that Economic sustainability has in fact increased the most. Performance data shows that the income index is 0.69 , GDP (US \$) is $350,000,000,000$, GDP per capita (2005 PPP \$) is 10,462, and gross domestic savings (\% of GDP) has gone from 30.8 in 1998 to 43.8 in 2007 (no data available for 2008-2012). Although the education index, and health index, both regarding social sustainability, are higher than the income index, it does 
not necessarily mean that Social sustainability is more developed than Economic sustainability, as other indicators also need to be in consideration. The most significant indicator showing that Economic growth is in fact more than what our data suggests, and is the most developed, is the fact that scientific development has significantly increased over the years, and will continue to grow. This is so because money is needed to be able to do research, and research itself brings in money, and so helps with the growth of the economy, both these facts put together means that a) the economy must have grown significantly, and the most, for the large increase in research, and b) the large amounts of research will have brought in huge amounts of money, so will have meant that the economy grew substantially more than social sustainability and environmental sustainability. The differences between our data and performance can again be attributed to the assumption that number of publications refers directly to output of research. As well as this, it could be because all areas can be said to drive and increase economy, so even though number of publications within the actual area of economic sustainability are few, overall the whole point of scientific development is to help the economy, and therefore they all reflect Economic sustainability, and so it is always the main focus.

Overall, performance data suggests that Economic sustainability has had the most significant increase, and has enjoyed the largest amount of growth, even though percentage increase shows that Social sustainability has increased the most. As well as this, the number of publications show that it is the area with the fewest amount of publications. So, though data shows Environmental sustainability has increased the most, performance data suggests that it has actually had the least growth. What is similar between our data and performance data, is that all areas of sustainability and overall scientific development have shown an increase/growth, which are a reflection of the increase in investment within science in Iran, the differences lie with regards to what specifically has increased the most.

However it is important to note that the performance of economic dimension of Iran was under imposed sanctions since 1979 by the U.S.A. US sanctions on Iran's economy intensified in 2011 and made a grave and negative impact on the economic dimension of sustainable development. Therefore, it is relatively difficult to find solid correlation between the publications in this category and performance.

\subsection{Does Scientific Development Support Sustainable Development?}

Although: focus has been changing over the years; certain areas such as Environmental sustainability have had higher production of publications; all dimensions have fluctuated to different degrees between 1998-2012; and over the years the dimensions have overtook each other, some more than others; the actual percentage increase in publications is similar. Obviously, the number of publications within each area will always show large differences, but it is the percentage change which is of actual interest, as it shows to what degree the area has increased or decreased over the years, thus showing to what degree they are being focused on. Taking this into account, in 2012 they all had similar percentage changes, with Social sustainability being the slightest fraction higher, at $448 \%$, Environmental sustainability and Economic sustainability are within $8 \%$ of each other, with Environmental sustainability at $394 \%$, and Social sustainability at $404 \%$. This percentage change does in fact reflect the general focus in Iran, with performance data also suggesting that the growth of the Economic area is more important than specific Environmental issues. From the data alone however, and the percentage change we can conclude that the 3 areas of sustainability are being dealt with simultaneously, with no area being definitively neglected, and all areas being looked into to a similar degree. They have also all undergone similar degree of transformation, meaning that all areas have shown a steady increase and a similar pattern of change to each other. Taking both points into consideration we can say that Iran's scientific development does in fact support sustainable development. The concept itself is however much more complicated than our data, and so if we take both into consideration, the answer to this question is still uncertain.

\subsection{Future Trends}

With the data we have, we are able to predict future trends, it seems obvious that the development in all areas will continue to increase, however we can already see a sort of plateau in the increase itself, so it may be that it will increase, but is now going to start to move at a more stable rate until it evens out to a certain level. As well as this, it seems that environmental issues such as pollution will continue to be second in importance, as Iran's main focus seems to be driving "more important" issues such as medicine, chemistry, physics etc, which will continue to be in the forefront in the future. However, as the United Nations Development Programme report suggests, it seems that Environmental sustainability is on the agenda, and will therefore hopefully show more improvement in the coming years. The trends also showed that social sustainability was slightly in the lead with regards to percentage increase, we think this may continue to be the case, as an increase in economic well-being is first and foremost intended to improve social well-being. 


\section{Conclusions}

In conclusion, we have tried to answer whether or not Iran's scientific development supports sustainable development. Our data has shown that scientific development has increased over the years, and publications in each area of sustainability has also increased, and although there is significantly more publications regarding Environmental sustainability compared to Social and Economic sustainability, it seems that the percentage increase in all areas is actually similar, which indicates that the focus in all areas is almost equal. Performance data from Iran confirms that all areas of sustainability have increased over the years, however there are differences regarding where the focus lies, with performance data suggesting that Economic sustainability is a major focus rather than Environmental. Overall, we can say that primary data shows that Iran's scientific development does to some degree support sustainable, as the percentage increase is similar in all areas, with the percentage increase in Social sustainability being slightly higher. What has become apparent from the research is that the topic encompasses many points and areas, and so giving a definitive answer is much more complicated then it first seems, due to the complexity of the topic a lot more further research is needed, before we can fully understand the situation. This should include collecting qualitative data, and looking at more databases for comparison, in order to get a much wider representation.

\section{References}

Atabi, F. (2004). Renewable energy in Iran: Challenges and opportunities for sustainable development. International Journal of Environment Science and Technology, 1(1), 69-80. http://dx.doi.org/10.1007/BF03325818

Carley, M., \& Christie, I. (2000). Managing Sustainable Development (2nd ed.). Earthscans Publication Ltd. Retrieved October 18, 2013, from http://books.google.co.uk/books?hl=en\&lr=\&id=lpup8TmpGC8C\& oi $=$ fnd\&pg=PR5\&dq=sustainable+development + in + iran\&ots=WcMlib-goJ\&sig=D4fYtE35CGGQAtbWR $6 \mathrm{~g} 7 \mathrm{WFs} Q V E A \# \mathrm{v}=$ onepage $\& \mathrm{q}=$ sustainable $\% 20$ development $\% 20 \mathrm{in} \% 20 \mathrm{iran} \& \mathrm{f}=\mathrm{false}$

Colantonia, A. (2007). Measuring Social Sustainability: Best Practice from Urban Renewal in the EU. Oxford Brooks University, pp 1-37.

Drake, D., \& Spinler, S. (2013). Sustainable Operations Management: An Enduring Stream or a Passing Fancy? $\begin{array}{lllll}\text { Manufacturing } \& \text { Service } & \text { Operations }\end{array}$ http://dx.doi.org/10.1287/msom.2013.0456

Etemad, S., \& Sobouti, Y. (2008). Trends in Basic Sciences in Contemporary Iran: Growth and Structure of Mainstream Basic Sciences, in Schweitzer, G. Science and Technology and the Future Development of Societies. International Workshop Proceedings. The National Academies Press, pp. 24-30.

FARS news agency. (2013). ISC: Iran Ranks 15 in World Science Production. FARS news, $14^{\text {th }}$ August. Retrieved October 18, 2013, from http://english.farsnews.com/newstext.aspx?nn=13920523001083

Global compact cities programme. (2013). Circles of sustainability. Retrieved October 18, 2013, from http://citiesprogramme.com/aboutus/our-approach/circles-of-sustainability

ISNA. (2015) ISC: Iranian Publication Quality. ISNA, 11th Jan [Online]. Retrieved from http://www.isna.ir/page/news-mobile.xhtml?newsCode=93102111139\&lang=fa\&m=1

Kharabaf, S., \& Abdollahi, M. (2012). Science growth in Iran over the past 35 years. Journal of Research in Medical Sciences, 17(3), 275-279.

Larsen, P. O., \& Ins, M. (2010). The rate of growth in scientific publication and the decline in coverage. provided by Science Citation Index. Scientometrics, 84(3), 575-603. http://dx.doi.org/10.1007/s11192-010-0202-z

Molanezhad, M. (2010). A Brief Review of Science and Technology and SMEs Development in I.R Iran. Ministry of Science, Research and Technology, and Iranian Research Organization for Science and Technology. Retrieved October 18, 2013, from http://unctad.org/Sections/un_cstd/docs/cstd2010d15_Iran_en.pdf

Murphy, K. (2012). The social pillar of sustainable development: a literature review and framework for policy analysis. Sustainability: Science, Practice \& Policy, 8(1), 15-29.

Partridge, E. (2005). Social sustainability': a useful theoretical framework? The Australasian Political Science Association Annual Conference, September 2005.

Sabetghadam, M. (2006). Energy and Sustainable Development in Iran. Helio International. Retrieved October 18, 2013, from http://sustainabledevelopment.un.org/content/documents/854Iran-EN.pdf
SCImago
Journal
and
Country
Rank.
(2013).
Retrieved
from 
http://www.scimagojr.com/countryrank.php?area $=0 \&$ category $=0 \&$ region=all\&year=2013\&order $=i t \& m i n=0$ \&min_type $=$ it

Soofi, A. S., \& Ghazinoory, S. (2013). Science and Innovations in Iran: Development, Progress, and Challenges. Palgrave Macmilliam, 1-274. http://dx.doi.org/10.1057/9781137030108

The World Bank Data. (2013). World Data Bank. Retrieved October 18, 2013, from http://databank.worldbank.org/data/views/reports/tableview.aspx.

United Nation Development Programme. (2013). Human Development Reports: Iran. Retrieved October 18, 2013, from http://hdr.undp.org/en/countries/profiles/IRN

United Nation Development Programme. (2013). United Nations Development Programme in the Islamic Republic of Iran: Country Programme 2012 - 2016. Retrieved October 18, 2013, from http://www.ir.undp.org/content/dam/iran/docs/IRAN-CO/IR-CountryProgramme2012-2016.pdf

World Commission on Environment and Development's (the Brundtland Commission) report, Our Common Future. Chapter 2: Towards Sustainable Development. UN Documents. (1987). Oxford University Press.

\section{Copyrights}

Copyright for this article is retained by the author(s), with first publication rights granted to the journal.

This is an open-access article distributed under the terms and conditions of the Creative Commons Attribution license (http://creativecommons.org/licenses/by/3.0/). 